\title{
Daniela, trastorno de la alimentación
}

Daniela, eating disorder

\section{María C. Feregrino-Carreón ${ }^{a}$, Felipe de J. Velarde-Ochoa ${ }^{b}$}

\begin{abstract}
:
Feading and eating disorders are importan in the clinical work for psychologist. Psychological intervention aims at listening and containing in order to assess objectively the situation the patient is, as well as change his/her life style so that he/she can recover mental and physical health. Daniela came for pshychological support following her mother's request. Her mother considered necessary that her daughter could express the restrained distress as an aid for medical-nutritional treatment that she were subjected to. Daniela talks about her disorder, her family history, her relationship to dancing and her future plans. The therapeutic process consisted of only three sessions. Through reconstruction of her history, present emotions, thoughts and conflicts are revealed.
\end{abstract}

Keywords:

Eating disorders, clinical work, sublimation

\section{Resumen:}

Los trastornos de la conducta alimentaria ocupan un lugar importante en el trabajo clínico del psicólogo. La intervención psicológica busca otorgar al paciente la escucha y la contención necesaria para evaluar de forma objetiva, las condiciones en las que se encuentra, así como las modificaciones a su estilo de vida que le permitan recobrar la salud. Daniela acude a consulta psicológica a petición de su madre, quien considera necesario que su hija pueda expresar el dolor contenido para así coadyuvar en el tratamiento medico-nutricional en el que se encuentra inserta. Ella habla de su enfermedad, de su historia familiar, de su relación con el baile y sus planes futuros. Este proceso terapéutico consta únicamente de tres sesiones, en las que a través de la reconstrucción de la historia pueden observarse las emociones, pensamientos y los conflictos presentes.

\section{Palabras Clave:}

Trastornos de la conducta alimentaria, trabajo clínico, sublimación

\section{Introducción}

Los trastornos de la conducta alimentaria (TCA) han sido objeto de la atención de diferentes disciplinas, considerándose actualmente un problema grave por la Organización Mundial de la Salud. Para Reixach, la alimentación está inmersa en un conjunto de referentes reales y simbólicos, en los que el mantenimiento y desarrollo de las funciones corporales ocupa uno de ellos. Cada region y época determinada otorga a la alimentación una serie de añadidos simbólicos, de manera que está íntimamente relacionado con la representación corporal. 1-2
El Manual Diagnóstico y Estadístico de los Trastornos Mentales V, reconoce ocho subtipos de trastornos de la conducta alimentaria (Pica, trastorno de rumiación, trastorno de evitación/restricción de la ingestion de alimentos, anorexia nerviosa, bulimia nerviosa, trastorno de atracones, otro trastorno de la conducta alimentaria no especificado, trastorno de la conducta alimentaria 0 de la ingestion de alimentos no especificado), mismos que en palabras de Hunot, se conceptualizan como multideterminados, no solo en su origen, sino también en los factores desencadenantes y de mantenimiento (Factores socioculturales, individuales, familiars y biológicos). 3-4

\footnotetext{
a Universidad Autónoma del Estado de Hidalgo, Escuela Superior de Atotonilco de Tula, ORCID: 0000-0001-5472-6892, Email: mariacristina_feregrino@uaeh.edu.mx

${ }^{\mathrm{b}}$ Autor de Correspondencia, Universidad Autónoma del Estado de Hidalgo, Escuela Superior de Atotonilco de Tula, Email: 
El presente caso clínico se ubica como Anorexia Nerviosa, debido a los síntomas que contempla desde su inicio hasta el período de tratamiento. En él se observa el establecimiento de la sublimación como mecanismo defensivo único para manejar el dolor que le provocan diversas situaciones familiares, mismo que en sí mismo no es un conflicto, sin embargo, al perderlo, permite la instalación de un trastorno depresivo que tiene como consecuencia la anorexia nerviosa.

\section{Daniela. La danza que sostiene el dolor}

Llegó con su madre un sábado en punto de la hora, justo el momento preciso de su primera cita. Maquillada de forma discreta, junto con un sonrisa y ropa cuidadosamente elegida, intentaba disimular el motivo de consulta.

- He estado muy triste y he perdido mucho peso

- dijo

¿Cuánto?

Casi 30 kilos

¿Cuánto pesas?

37 kilos

Después de verificar el seguimiento médico y nutricional, le pedí a su madre me dejara sola con ella, Daniela era su nombre.

Me contó cómo había comenzado su problema:

Hace un año dejé de bailar, tuve una fisura en el hombro que si no la cuidaba corría el riesgo de convertirse en una fractura múltiple, prácticamente irreparable. Dejé la danza, fue muy triste porque con ella yo era capaz de expresarlo todo.

Ella comenzó a bailar cuando era muy pequeña, recuerda que le gustaba mucho, pero después del divorcio de sus padres, comenzó a hacerlo disciplinadamente (cuasi de forma profesional).

El baile le otorgó un sinfín de habilidades: podía maquillarse de forma que representara distintos estados de ánimo, arreglar su cabello para transformarlo y que pasara desapercibido o incluso para convertirlo en una mini escultura, aprendió a manejar su imagen y representar con ella lo que deseara.

La lesión en su hombro, en palabras de su médico era irreversible y permanente. Los estudios mostraban una serie de microfisuras no tratadas, que con el paso del tiempo generaron una situación de fragilidad, imposible de solucionar.

No me centré en el peso, sino en sus recuerdos ¿qué pasó?, ¿cómo estabas?, ¿cómo te sentías?

Comenzó contándome que cuando recibió la noticia del médico se sintió muy triste, ya no podía practicar y en caso necesario ensayar para los eventos (la práctica era tres veces por semana y cuando ensayaban para una presentación, lo hacía hasta por cuatro horas diarias), al mes de dejar la danza había ya ganado casi diez kilos y no me gustaba como me veía, por lo que comenzó a disminuir paulatinamente su ingesta de alimentos hasta reducirla a un par de manzanas o un trozo de lechuga al día. Logró bajar rápidamente de peso, tanto los diez kilos aumentados como 13 más, ella se sentía plena con los comentarios positivos de sus compañeros de grupo, había considerado que el peso ideal para ella era de 45 kilos, sin embargo, al llegar a la meta (seis meses), su cuerpo no respondió y a pesar de ingerir una cantidad mayor de alimentos siguió perdiendo peso, hasta llegar a los 37 kilogramos en un lapso de 12 meses. Logró disimular la pérdida de peso gracias a su habilidad para maquillarse, manejar su cabello y la ropa que portaba.

Ella intentaba que los recuerdos no la desbordasen, buscaba eliminar sus lágrimas, acallar sus sollozos. Le pedí que se dejase cuidar, que ahora casi catorce años después podría mostrar sus sentimientos, su enojo, su desamparo, su impotencia.

Después de meses de violencia entre sus padres e inclusive hacia ella y sus hermanos menores, su madre decide divorciarse. Su padre se aleja durante un año entero, mientras que su madre busca un segundo empleo y busca que sus hijos sean autónomos e independientes. Lo logra, cada uno de ellos realiza sus actividades de forma ordenada y responsable, siempre bajo la mirada cariñosa y protectora de Dani, quien para lograrlo se refugia en el baile.

La primera sesión terminó solicitándole que siguiera las instrucciones de su médico, que permitiera que su madre la llamara y le preguntara por sus alimentos. También le pedí que solicitara ayuda a sus amigos para que la recogiesen en la entrada de la facultad y se sintiese cómoda al caminar (lentamente y casi sin aliento), los quince minutos hasta el aula.

La vi el siguiente domingo, cálida y sonriente. Me contó que había ganado dos kilos, pero que había sido una grata experiencia permitir que su familia y amigos la cuidaran.

Salió a la feria con sus hermanos, su madre y su papá. Él le compró un banquito de madera plegable para que ella descansara cuando así lo decidiera. Todos hicieron bromas, caminaron lentamente mientras disfrutaron de la tarde.

La relación con su padre fue difícil desde que vivían juntos, en aquél entonces él era un hombre violento y cuando regresó un año después, viviendo en un departamento, se excusaba culpando de todo a la madre, incluso del abandono. No recuerda el momento exacto, pero él comenzó a mentir de forma continua y 
exagerada. Por ejemplo, a ella y solo a ella cuando tenía 12 años, le contó que tenía cáncer terminal y que no se lo contara a nadie, ella mantuvo el secreto, sufriendo por su padre. Casi diez años después él insiste que tiene cáncer y que es un milagro que esté con vida.

- Él se convirtió en un "cajero automático", pues era difícil amarlo plenamente con una vida plagada de mentiras. Tristemente mis hermanos $y$ yo aprendimos a creerle a medias, a dudar de casi todo lo que decía para no sufrir, aunque sabíamos que a su modo nos amaba.

Hablar de su padre le es difícil, pero lo intenta, busca encontrar formas para entenderlo, para perdonarlo e incluirlo en su futuro.

A sus amigos les pidió ayuda durante la semana, con uno lo hizo en lunes y luego acompañada de él, lo compartió con el otro el miércoles. Les contó su miedo y su debilidad y aunque ellos le pidieron que no llorara, se ofrecieron a acompañarla y amarla en todo momento.

En esta ocasión y a pesar de las lágrimas derramadas, Dani se despidió con una sonrisa.

El siguiente sábado acudió como las ocasiones anteriores: pulcra, sonriente y puntual.

Retomamos la situación con su imagen y sus planes, aunque ella puso énfasis en su estado de ánimo durante la semana: admitió haber llorado mucho. Por un lado, por su tos aguda que no la dejó en paz y también por pensar en todos los planes que habrían de cumplirse en diciembre y que ahora ya no se concretarían.

Ella tenía un novio. Lo conoció en la Universidad, en su grupo, le parecía un hombre diferente, extraordinariamente inteligente y amable, de buenas maneras y con grandes proyectos.

Al principio salían y se divertían muchísimo, sin embargo, él buscaba su apoyo y aprobación en cada momento, mismas que cuando ella necesitaba o pedía no existían; aún con eso planeaban emigrar a provincia y vivir juntos. Conforme pasaba el tiempo la comunicación entre ellos era cada vez más deficiente y ella decidió terminar (hace tres meses). Lo más doloroso para ella, fue ver como él retomó sus planes inmediatamente (los planes compartidos), sin ella, con otra persona.

Le pedí que se imaginara su vida con él y sonrió: no le gustó, no se le antojaba. Comenzó entonces a planear qué hacer con su familia y amigos gracias al tiempo que ahora tenía.

Tuvo un acceso de tos combinado con ansiedad, después me dijo que le daba "muchísima vergüenza" toser frente a las personas, también me dijo que su mamá le preguntó por qué se aferraba a eso.

Enlazó su tos a la profunda tristeza que sentía por su relación perdida y el temor a perder el peso que recién había ganado.

También había hablado con su hermano menor en la semana, se sorprendió al escuchar una versión diferente de la historia de sus padres y del posterior divorcio. Le pareció irreal e inocente y no quiso mancharla con sus propios recuerdos, sin embargo, reconoció la necesidad de ambos de compartir y reconstruir su historia, de forma que se complementara objetivamente, para no verla como hermosa o terrible, sino tal cual.

Su mamá entró después, dijo estar preocupada, pero al mismo tiempo tranquila, preocupada por la condición física y no saber qué hacer con la tristeza de su hija, pero tranquila por verla dispuesta a compartir, a dejarse cuidar y apapachar por ellos.

Quedamos de vernos la siguiente semana, pero Dani canceló la cita el lunes, pues presentó un cuadro de neumonía, con la recomendación médica de permanecer en reposo.

El siguiente martes, posterior a la cita cancelada, su madre me envió el siguiente mensaje por la mañana:

"Le agradezco todas sus atenciones para conmigo y mi hija, le ayudaron para que partiera de este mundo con mucha tranquilidad, mi niña falleció el sábado pasado"

\section{Conclusiones}

Los TCA requieren una intervención interdisciplinaria debido a que se comprometen diferentes sistemas en su desarrollo: medicina interna, psiquiatría nutrición, psicología. Mantener la vigilancia durante las diferentes fases de la enfermedad, a fin de preservar la vida y la integridad de los sistemas implicados.

La intervención terapéutica contempla el establecimiento de un espacio de contención y atención al paciente que le permita explorar las áreas dolorosas en su historia y en su presente.

Daniela encontró en la danza la forma para manejar la tristeza y el dolor que había vivido en la relación familiar, así como las dificultades de su día a día. La sublimación implica la canalización de la energía psíquica para evitar el dolor-displacer, mediante construcciones socialmente aceptadas. El problema para Daniela consistió en dos puntos principales: el primero: elegirlo como el único medio para manejar sus conflictos, el segundo, en el plano de la realidad: la fisura del hombro: la incapacidad de mantener cualquier tipo de actividad aeróbica que le permitiera tanto descargar la energía física acumulada, como 
mantener su cuerpo en una condición adecuada. El proceso terapéutico permitió a Daniela explorar sus emociones y sentimientos, acercarse a su historia y enlazarse a ella, permitirse ser hija, hermana, amiga y abrazar desde esa perspectiva a sus seres queridos.

\section{Referencias}

[1]López C. Carolina, T. J. (2011). Trastornos de la conducta alimentaria en adolescentes: descripción y manejo. Revista Clínica Médica Las Condes, 85-97.

[2]Reixach, C. (2005). La alimentación en la cultura egipcia. En J. $\mathrm{S}$. Salvadó, La alimentación y la nutrición a través de la historia (págs. 35-61). Barcelona: Glosa.

[3]American Psychiatric Association. (2014). Manual Diagnóstico y Estadístico de los Trastornos Mentales V. México: Panamericana.

[4]Hunot, C. V. (2008). Definición conceptual de las alteraciones de la conducta alimentaria. Revista Salud Pública y

Nutrición, 1-21 